\title{
Pro-inflammatory and oxidative stress pathways which compromise sperm motility and survival may be altered by L-carnitine
}

Adel R.A. Abd-Allah, ${ }^{*}$ Gouda K. Helal, Abdulaziz A. Al-Yahya, Abdulaziz M. Aleisa, Salim S. Al-Rejaie and Saleh A. Al-Bakheet

Department of Pharmacology; College of Pharmacy; King Saud University; Riyadh, Saudi Arabia

Key words: LPS, L-carnitine, blood-testes barrier, immune regulation, oxidative stress

The testis is an immunologically privileged organ. Sertoli cells can form a blood-testis barrier and protect sperm cells from self-immune system attacks. Spermatogenesis may be inhibited by severe illness, bacterial infections and chronic inflammatory diseases but the mechanism(s) is poorly understood. Our objective is to help in understanding such mechanism(s) to develop protective agents against temporary or permanent testicular dysfunction. Lipopolysaccaride (LPS) is used as a model of animal sepsis while L-carnitine (LCR) is used as a protective agent. A total of 60 male Swiss albino rats were divided into four groups (15/group). The control group received Saline; the $2^{\text {nd }}$ group was given LCR $(500 \mathrm{mg} / \mathrm{kg}$ i.p, once). The third group was treated with LPS ( $5 \mathrm{mg} / \mathrm{kg}$ i.p once) and the fourth group received LCR then LPS after three hours. From each group, five rats were used for histopathological examination. Biochemical parameters were assessed in the remaining ten rats. At the end of the experiment, animals were lightly anaesthetized with ether where blood samples were collected and testes were dissected on ice. Sperm count and motility were evaluated from cauda epididymis in each animal. Also, oxidative stress was evaluated by measuring testicular contents of reduced glutathione (GSH), malondialdehyde (MDA) and 8-hydroxydeoxyguanosine (8-HDG, the DNA adduct for oxidative damage) in testicular DNA. The pro-inflammatory mediator nitric oxide (NO) in addition to lactate dehydrogenase $(\mathrm{LDHx})$ isoenzyme- $\mathrm{x}$ activity as an indicator for normal spermatozoal metabolism were assessed in testicular homogenate. Serum interlukin (IL)-2 level was also assessed as a marker for T-helper cell function. The obtained data revealed that LPS induced marked reductions in sperm's count and motility, obstruction in seminiferous tubules, hypospermia and dilated congested blood vessels in testicular

*Correspondence to: Adel R.A. Abd-Allah; Department of Pharmacology; College of Pharmacy; King Saud University; P.O. Box 2457; Riyadh 11451 Saudi Arabia; Tel.: +966.4677263; Fax: 09664677200; Email: arabdallah@hotmail.com

Submitted: 02/11/09; Revised: 02/14/09; Accepted: 02/16/09

Previously published online as an Oxidative Medicine and Cellular Longevity E-publication:

http://www.landesbioscience.com/journals/oximed/article/8177 sections concomitant with decreased testicular GSH content and LDHx activity. Moreover, the testicular levels of MDA, 8-HDG (in testicular DNA) and NO as well as serum IL-2 level were increased. Administration of LCR before LPS returned both sperm count and motility to normal levels. Also, contents of testicular GSH, MDA, 8-HDG and NO returned back to the corresponding control values. In addition, serum IL-2 level as well as histological abnormalities were markedly improved in LCR + LPS-treated rats. In conclusion, LPS increased proinflammatory and oxidative stress markers in the testis leading to a marked testicular dysfunction. L-carnitine administration ameliorates these effects by antioxidant and/or anti-inflammatory mechanisms suggesting a protective role against male infertility in severely infected or septic patients.

\section{Introduction}

Studies have demonstrated that the testis is the most resistant to various forms of non-autoimmune inflammation among the male reproductive organs. ${ }^{1}$ The authors explained that the tubuli recti (TR) in the testis comprises a specific region where lymphocytes are attracted. Many antigen-presenting macrophages preferentially accumulate around the TR under normal conditions. This characteristic accumulation of macrophages is an acquired phenomenon that is completed when spermatids start to differentiate in the seminiferous tubules. ${ }^{2}$ Furthermore, intra-tubular lymphocytes that are very close to both germ cells and their remnants could be occasionally found in the TR, rete testis and epididymis, but not in the seminiferous tubules, in normal animals. ${ }^{3}$ Although the physiological function of these penetrating lymphocytes remains unknown, it was supposed that this micro-status provides a chance for evocation of immune reaction in some pathological conditions. ${ }^{1}$

Microbial infections, either localized or systemic, can lead to male infertility; however, the precise mechanisms by which such infections impair the male reproductive system are not completely understood. ${ }^{4}$ Recent evidence suggests that the system governing spermatogenesis includes immune cell types, and testicular cells where they affect each other and are controlled to some extent by each other. ${ }^{5}$ The regulation of spermatogenesis involves both 
endocrine and paracrine mechanisms. ${ }^{4}$ The testis has a unique immune structure that helps in maintenance of spermatogenesis apart from immune system recognition. ${ }^{6}$ This may be designated as an immune-testicular barrier which can explain the increased $\mathrm{CD}^{+} / \mathrm{CD}^{+}$ratio in the testis to that in the circulation. ${ }^{7}$ The presence of macrophages as phagocytic as well as antigen-presenting cells, ${ }^{6}$ has a cross-talk effect with Leyding cells that may play a role in normal spermatogenesis. Therefore, balance to the immune structure is important to keep suitable media for normal spermatogenesis.

Infection and/or inflammation may be implicated in dysregulation of the normal spermatogenesis. ${ }^{8}$ It has been established that a condition similar to infection can be produced in vivo by administration of bacterial LPS. In that regard LPS administration was found to inhibit testicular steroidogenesis and the disruption of spermatogenesis in animals. ${ }^{9}$ Cytokines are good candidates for involvement in the local control exerted between germ and Sertoli cell activity. ${ }^{10}$ High levels of certain cytokines are often linked with a decrease in the quality of the seminological parameters. ${ }^{11}$ The same cytokines that act as elements of immunomodulation for the male gonad appear in large concentrations in semen during infection and their participation in inflammation is closely connected with the accompanying leukocytospermia. ${ }^{6}$

In the course of the inflammatory process, the excessive production of ROS is most probably caused by additionally recruited leukocytes, which take part in this reaction and may disturb the balance of pro-oxidative and antioxidative factors. ${ }^{12}$ Concomitant with the start of phagocytosis during inflammation, the oxygen metabolism by leukocytes accelerates and is connected with the production and release of large amounts of superoxide anion $\left(\mathrm{O}_{2}^{-}\right)$ and hydrogen peroxide $\left(\mathrm{H}_{2} \mathrm{O}_{2}\right){ }^{12,13}$ Secreted proinflammatory cytokines are the next mediators of the host response to infection, and they modulate the activities of the prooxidative and antioxidative systems to the advantage of the ROS. ${ }^{14,15}$ When the amounts of ROS exceed the potential of the antioxidant defense, peroxidative damage to the spermatozoa occurs. ${ }^{16}$ It has been suggested that the reduced total antioxidant capacity of seminal plasma is sufficient to ensure sperm abnormalities. ${ }^{16-18}$

Recently, apoptosis has been documented to play an important role in spermatogenesis in the human testis. ${ }^{19}$ Increased apoptosis, along with hypospermatogenesis, have been reported in infertile men. ${ }^{20,21}$ The increased cytokines can lead to a permanent loss of spermatogenesis which was related to germ cell apoptosis. ${ }^{16}$ However, its cause(s) and the molecular mechanism(s) are poorly understood. ${ }^{15}$ In addition, DNA damage may be a trigger for this process. ${ }^{6}$ Therefore, the influence of testicular DNA integrity on normal spermatogenesis has gained much attention in the past few years. ${ }^{16}$

L-Carnitine ( $\gamma$-trimethylamino- $\beta$-hydroxybutyrate) is synthesized in vivo from methionine and lysine. ${ }^{22}$ It is assumed that in normal circumstances, the biosynthesis of L-carnitine is sufficient to meet metabolic requirements, though for newborns and in several disease situations (apart from primary carnitine deficiency) oral L-carnitine supplements may be necessary as therapy. ${ }^{23}$ The primary function of L-carnitine is to act as a carrier for translocation of long-chain fatty acids from the cytosol into mitochondria for $\beta$-oxidation, hence sustaining the supply of energy. ${ }^{24}$ However,

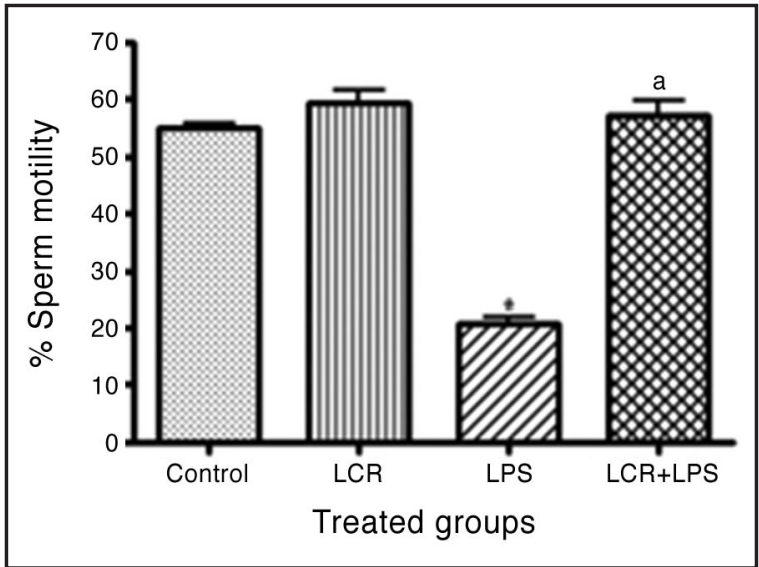

Figure 1. L-carnitine (LCR) reserved lipopolysaccharide (LPS)-induced inhibition of sperm motility in rats. Data are expressed as means \pm SEM $(\mathrm{N}=10)$. LPS was given i.p in a dose of $5 \mathrm{mg} / \mathrm{kg}$ once and parameters were assessed $24 \mathrm{~h}$ later. LCR was given i.p in a dose of $500 \mathrm{mg} / \mathrm{kg}$ once alone or $3 \mathrm{~h}$ before LPS. Control group received saline. Statistical comparison between different groups were done using one way analysis of variance (ANOVA) and followed by Tukey-Kramer for a multiple comparisons test at $p<0.05$. $\left({ }^{*}, a\right)$ indicate differences from control and LPS-treated groups, respectively.

besides this well-known effect, there is growing evidence that L-carnitine also plays a role in other physiological processes in humans and animals. Indeed, L-carnitine and some of its acyl esters act as very potent reactive oxygen species scavengers ${ }^{25,26}$ and are known to have immunomodulatory properties in mammalian as well as avian species. ${ }^{27}$ Although recent studies have attended to the role of L-carnitine in treatment of male infertility during sepsis, the exact mode of action still needs to be explored. Li et al. $^{28}$ explained that the level of free L-carnitine in seminal plasma is significantly correlated with sperm count, motility and vitality. Also, De Rosa et al. ${ }^{29}$ concluded that, L-carnitine/L-acetylcarnitine treatment may be an effective therapy to improve mainly functional seminal parameters. L-carnitine has been reported as a glucocorticoid mimicker because it activates the intracellular glucocorticoid receptor- $\alpha$ and modulates the expression of glucocorticoid-dependent genes during inflammation. ${ }^{30-32}$ Glucocorticoids have a suppressive effect on the synthesis of proinflammatory cytokines by macrophages, and this effect was mimicked by L-carnitine. ${ }^{27}$ Based on the aforementioned information, LCR has been selected in the present work as a possible protective agent.

The rationale of the present study is to help in understanding the exact mechanism(s) of LPS-induced male infertility as well as the possible protective role of LCR in severely infected or septic patients. This may shed light on the usefulness of LCR as a safe natural product in such pathological situations.

\section{Results}

Sperm counts and motility as markers for normal testicular function. The present data show that LPS administration induced significant reductions in both sperm numbers and motility to the extents of $79.5 \%$ (Fig. 1) and $37.9 \%$ (Fig. 2), respectively, from their corresponding control groups. Administration of LCR three 


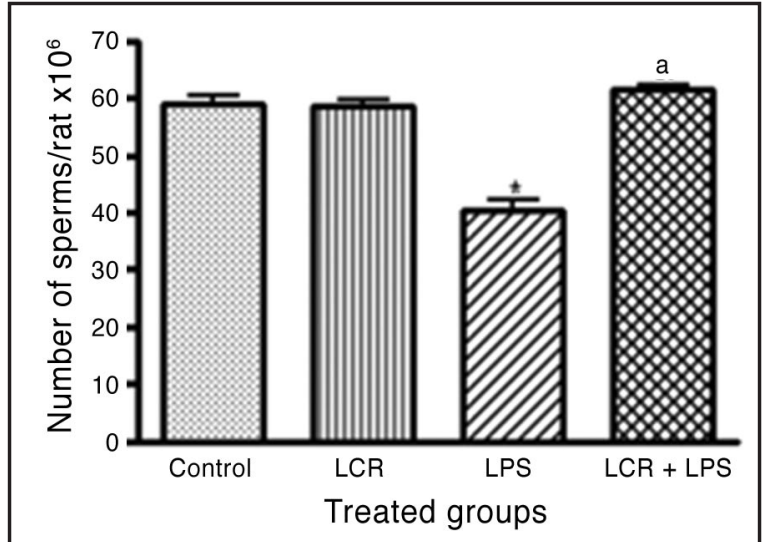

Figure 2. L-carnitine (LCR) reserved lipopolysaccharide (LPS)-induced inhibition of sperm count in rats. Data are expressed as means \pm SEM $(\mathrm{N}=10)$. LPS was given i.p in a dose of $5 \mathrm{mg} / \mathrm{kg}$ once and parameters were assessed $24 \mathrm{~h}$ later. LCR was given i.p in a dose of $500 \mathrm{mg} / \mathrm{kg}$ once alone or $3 \mathrm{~h}$ before LPS. Control group received saline. Statistical comparison between different groups were done using one way analysis of variance (ANOVA) and followed by Tukey-Kramer for a multiple comparisons test at $p<0.05$. $\left({ }^{*}, a\right)$ indicate differences from control and LPS-treated groups, respectively.

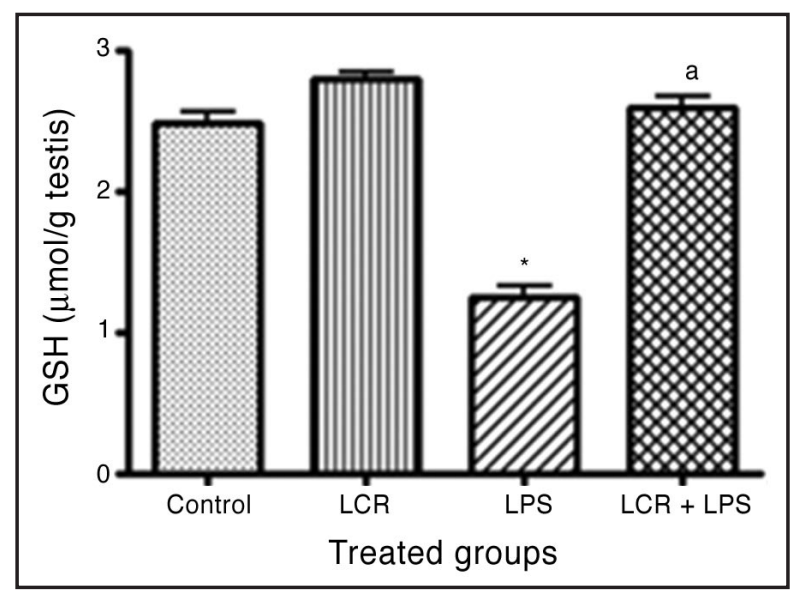

Figure 4. L-carnitine (LCR) reserved lipopolysaccharide (LPS)-induced depletion of testicular glutathione (GSH) content in rats. Data are expressed as means \pm SEM $(N=10)$. LPS was given i.p in a dose of $5 \mathrm{mg} / \mathrm{kg}$ once and parameters were assessed $24 \mathrm{~h}$ later. LCR was given i.p in a dose of $500 \mathrm{mg} / \mathrm{kg}$ once alone or $3 \mathrm{~h}$ before LPS. Control group received saline. Statistical comparison between different groups were done by using one way analysis of variance (ANOVA) and followed by Tukey-Kramer for multiple comparisons test at $p<0.05 .\left({ }^{*}, a\right)$ indicate differences from control and LPS-treated groups, respectively.

hours before LPS restored completely both sperm numbers and motility as shown in Figures 1 and 2, respectively.

Testicular GSH content as a marker for redox potential. Data in Figure 3 explain that rats treated with LPS exhibited significantly reduced testicular GSH content to be $50.4 \%$ from the corresponding control values.

LCR - treated rats (three hours before LPS) showed normal testicular GSH level as there was no significant difference from the corresponding control values (Fig. 3).

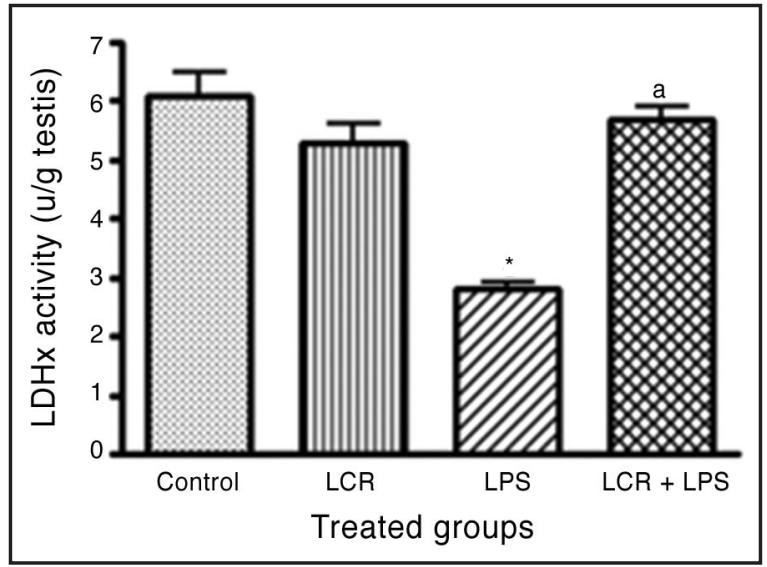

Figure 3. L-carnitine (LCR) reserved lipopolysaccharide (LPS)-induced inhibition of $L D H x$ activity in rats. Data are expressed as means \pm SEM $(\mathrm{N}=10)$. LPS was given i.p in a dose of $5 \mathrm{mg} / \mathrm{kg}$ once and parameters were assessed $24 \mathrm{~h}$ later. LCR was given i.p in a dose of $500 \mathrm{mg} / \mathrm{kg}$ once alone or $3 \mathrm{~h}$ before LPS. Control group received saline. Statistical comparison between different groups were done using one way analysis of variance (ANOVA) and followed by Tukey-Kramer for a multiple comparisons test at $p<0.05 .(*, a)$ indicate differences from control and LPS-treated groups, respectively.

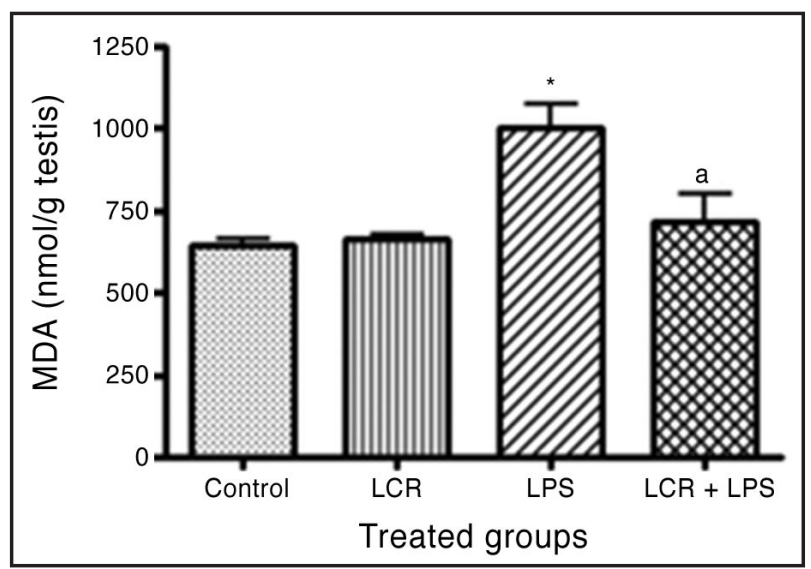

Figure 5. L-carnitine (LCR) prevented lipopolysaccharide (LPS)-induced increase in testicular malondialdehyde (MDA) content in rats. Data are expressed as means \pm SEM $(N=10)$. LPS was given i.p in a dose of 5 $\mathrm{mg} / \mathrm{kg}$ once and parameters were assessed $24 \mathrm{~h}$ later. LCR was given i. $p$ in a dose of $500 \mathrm{mg} / \mathrm{kg}$ once alone or $3 \mathrm{~h}$ before LPS. Control group received saline. Statistical comparison between different groups were done using one way analysis of variance (ANOVA) and followed by Tukey-Kramer for a multiple comparisons test at $p<0.05 .\left({ }^{*}, a\right)$ indicate differences from control and LPS-treated groups, respectively.

Testicular MDA content as a marker for lipid peroxides formation. As indicated in Figure 4, LPS administration resulted in a marked increase of the MDA level in rat testes to be $155 \%$ of the control value.

When LCR was injected into rats three hours before LPS administration, it prevented the increase in testicular MDA level returning it back to the control value (Fig. 4).

Testicular nitric oxide (NO) content as a proinflammatory mediator. Injection of LPS into rats produced an extensive induction 


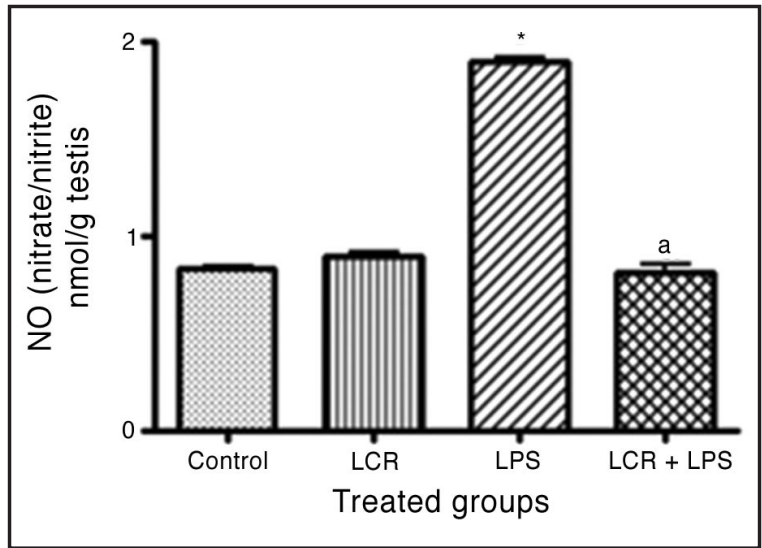

Figure 6. L-carnitine (LCR) prevented lipopolysaccharide (LPS)-induced increase in testicular nitric oxide $(\mathrm{NO})$ content in rats. Data are expressed as means \pm SEM ( $N=10$ ). LPS was given i.p in a dose of $5 \mathrm{mg} / \mathrm{kg}$ once and parameters were assessed $24 \mathrm{~h}$ later. LCR was given i.p in a dose of $500 \mathrm{mg} / \mathrm{kg}$ once alone or $3 \mathrm{~h}$ before LPS. Control group received saline. Statistical comparison between different groups were done using one way analysis of variance (ANOVA) and followed by Tukey-Kramer for a multiple comparisons test at $p<0.05 .\left({ }^{*}, a\right)$ indicate differences from control and LPS-treated groups, respectively.

of $\mathrm{NO}$ in the testis measured as nitrate/nitrite to reach a $128.9 \%$ increase than the corresponding control value (Fig. 5).

Such increase in the testicular NO showed marked reduction in rats pretreated with LCR (3 hours before LPS) to reach the normal control value (Fig. 5).

Testicular LDH-x isoenzyme activity $\mathrm{t}$ as a marker for normal spermatozoal metabolism. The activity of LDH-x enzyme in the testes of rats treated with LPS showed marked reduction by $55.10 \%$ than the corresponding control group (Fig. 6).

In the testes of rats injected with LCR (three hours before LPS) the activity of LDH-x showed no significant difference from those of the corresponding controls (Fig. 6).

Testicular DNA-extracted 8-HDG adduct as a marker for oxidative damage. Figure 7 explains that LPS administration resulted in more than four-fold increase in testicular DNA-extracted 8-HDGas compared to the corresponding control values. preadministration of LCR markedly reduced the increased 8-HDG level in LPS-treated rats to the extent of $136 \%$ of the control values.

Serum IL-2 as a marker for T-helper cell function. Results of the present work illustrate that LPS injection significantly increased serum IL-2 level in rats by $176.8 \%$ than the corresponding control value (Fig. 8). Preadminstration of LCR (three hours before LPS) resulted in a significant reduction in serum IL-2 than only LPS-treated animals by $118.3 \%$ although it was still show an increased level than the control group by $62 \%$ (Fig. 8).

Histopathological examination. Figure 9 shows a photomicroscopic picture for testicular section stained with $\mathrm{H}$ and $\mathrm{E}$ from a control rat shows normal histological structure of the seminiferous tubules and Leyding cells.

LPS administration resulted in inflammation, necrotic and sloughed lining with incomplete or absent spermatogenesis (Fig. 10).

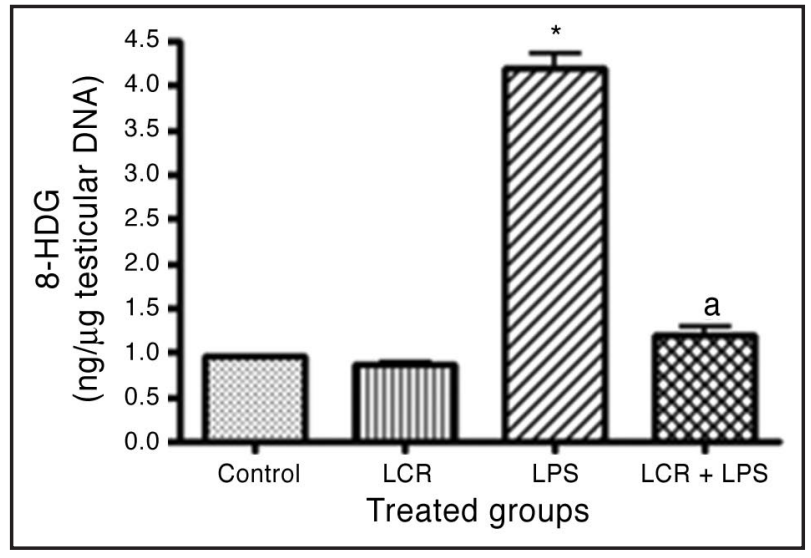

Figure 7. L-carnitine (LCR) prevented lipopolysaccharide (LPS)-induced increase in 8-hydroxydeoxyguanosine (8-HDG) content in rat testicular DNA. Data are expressed as means \pm SEM $(N=10)$. LPS was given i.p in a dose of $5 \mathrm{mg} / \mathrm{kg}$ once and parameters were assessed $24 \mathrm{~h}$ later. LCR was given i.p in a dose of $500 \mathrm{mg} / \mathrm{kg}$ once alone or $3 \mathrm{~h}$ before LPS. Control group received saline. Statistical comparison between different groups were done using one way analysis of variance (ANOVA) and followed by Tukey-Kramer for a multiple comparisons test at $p<0.05$. $\left({ }^{*}, a\right)$ indicate differences from control and LPS-treated groups, respectively.

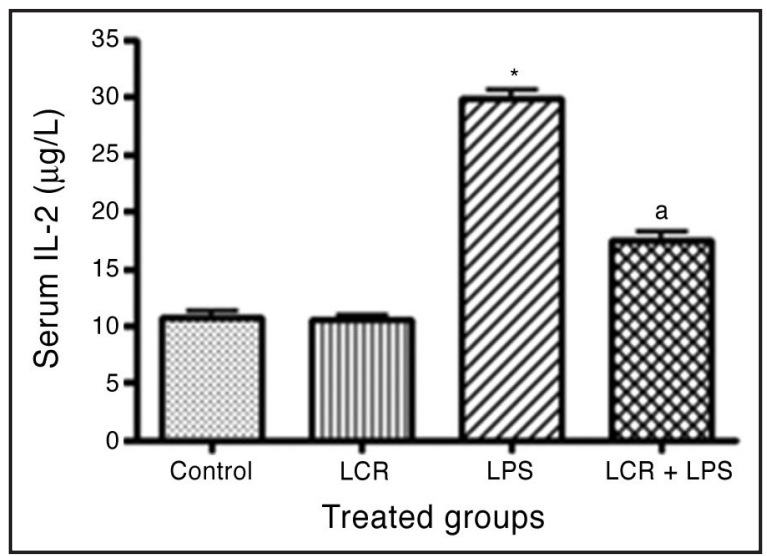

Figure 8. L-carnitine (LCR) prevented lipopolysaccharide (LPS)-induced increase in serum interlukin-2 (IL-2) in rats. Data are expressed as means \pm SEM $(\mathrm{N}=10)$. LPS was given i.p in a dose of $5 \mathrm{mg} / \mathrm{kg}$ once and parameters were assessed $24 \mathrm{~h}$ later. LCR was given i.p in a dose of $500 \mathrm{mg} / \mathrm{kg}$ once alone or $3 \mathrm{~h}$ before LPS. Control group received saline. Statistical comparison between different groups were done using one way analysis of variance (ANOVA) and followed by Tukey-Kramer for a multiple comparisons test at $p<0.05 .\left({ }^{*}, a\right)$ indicate differences from control and LPS-treated groups, respectively.

In LCR + LPS-treated rats there is improved histological structure of the seminiferous tubules with marked decrease in leukocyte infiltration and inflammation (Fig. 11).

\section{Discussion}

The direct association between acute or chronic infection and/ or inflammation in the male reproductive system and the subsequent development of infertility constitute important issues in 


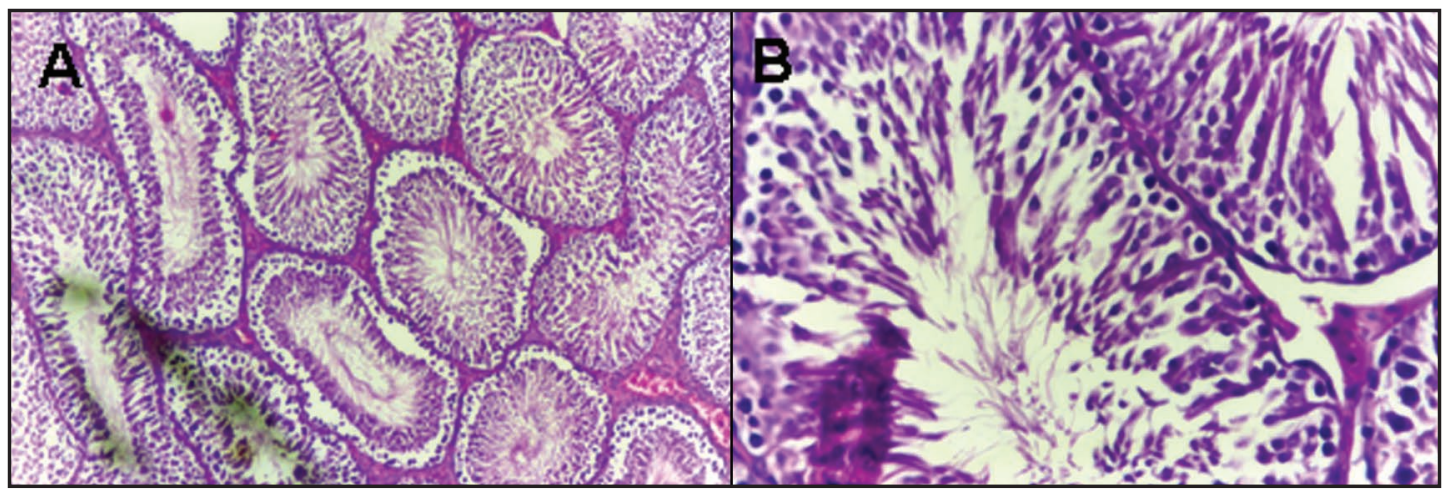

Figure 9. A photomicroscopic picture for testicular section stained with $\mathrm{H}$ and $\mathrm{E}$ from a control rat received saline shows normal histological structure of patent seminiferous tubules with complete spermatogenesis. $(A)=20 x ;(B)=40 x$.

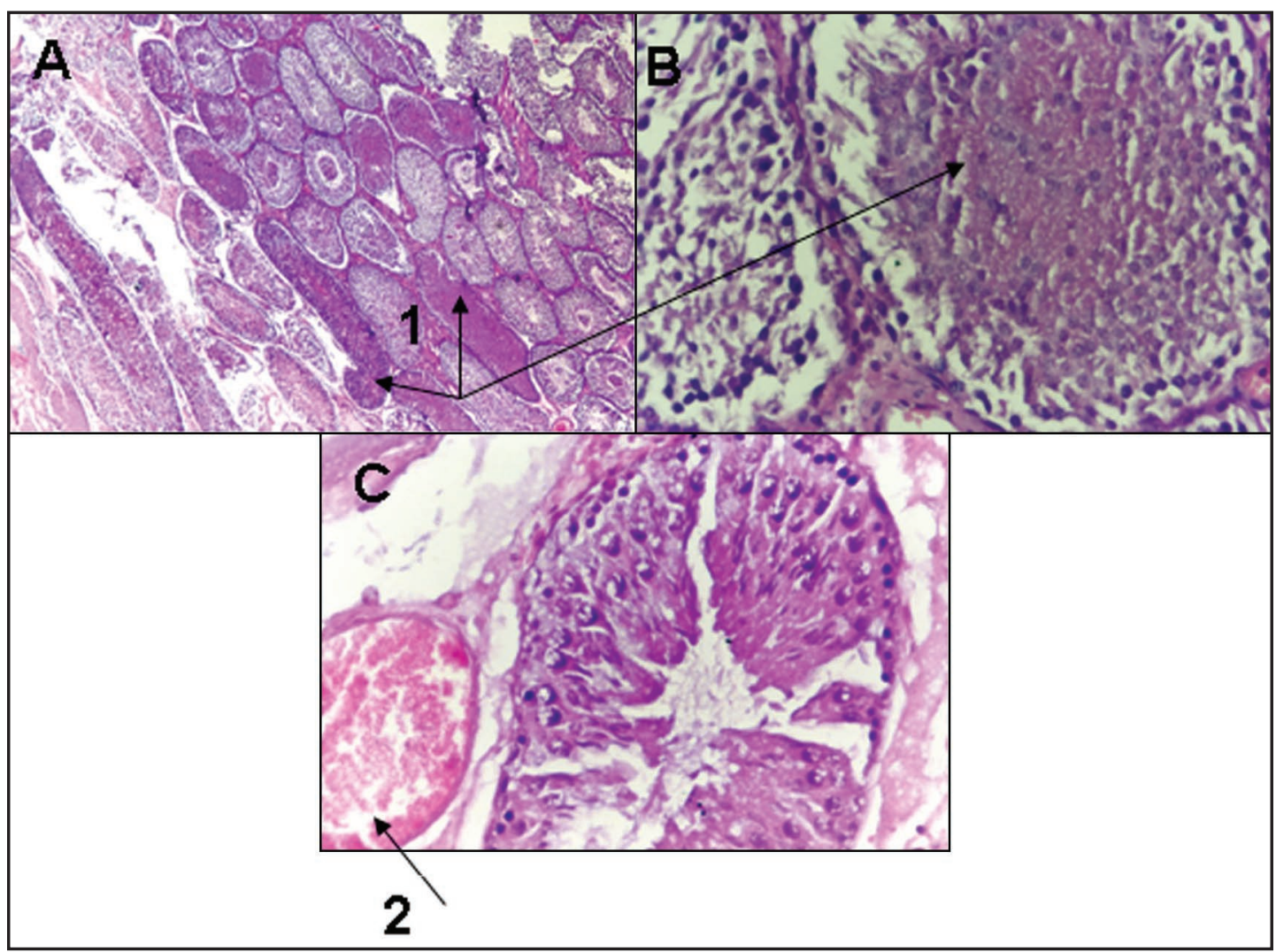

Figure 10. A photomicroscopic picture for testicular sections from LPS-treated rats stained with $\mathrm{H}$ and $\mathrm{E}$ showing hypospermatogenesis at different levels of maturation. Some tubules are occupied by hyaline materials floating, scattered, sloughed spermatogenic cells (A), 20X and (B), 40X: arrow 1. Congested dilated interstitial blood vessel as one marker for inflammation is shown in picture (C), 40X (arrow 2). LPS was given i.p in a dose of 5 mg/ kg once.

contemporary medicine. ${ }^{16}$ The integrity of the blood-testis barrier and the development of immunoregulatory mechanisms in the testis are essential for preservation of reproductive capacity. ${ }^{7}$

It has been proposed that infection may lead to impairment of the blood-testis barrier, as well as immune regulatory mechanisms, and induce male infertility. ${ }^{6}$ In the present study, microscopic and histological examinations revealed that exposure of rats to LPS resulted in marked decreases in sperm count as well as motility. The abnormal infiltration of lymphocytes, as well as granulocytes, may lead to inflammation indicated by deteriorated histological features as compared to control animals. Also, biochemical investigations showed that testes of rats exposed to LPS exhibited highly significant increases in the levels of MDA and NO, accompanied with significant decreases in testicular GSH content and a marked decrease in the activity of $\mathrm{LDH}_{\mathrm{x}}$ in comparison with the control rats. Serum IL-2 level also showed a marked increase in LPS-treated rats. These data are in harmony with the previous studies which revealed that infection and inflammation after administration of 


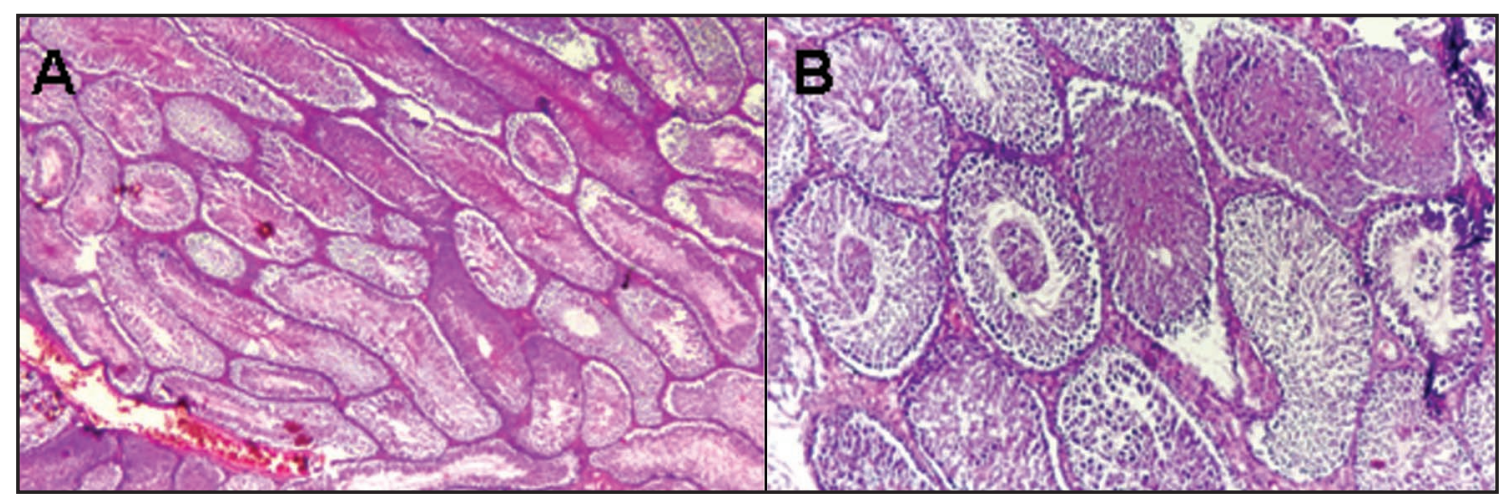

Figure 11. A photomicroscopic picture for testicular section stained with $\mathrm{H}$ and $\mathrm{E}$ from LCR + LPS-treated rat showing improved histological structure of the seminiferous tubules and spermatogenesis with marked reduction in blood vessel congestion. (A) 20X; (B) 40X. LCR was given i.p in a dose of 500 $\mathrm{mg} / \mathrm{kg}$ once $3 \mathrm{~h}$ before LPS $(5 \mathrm{mg} / \mathrm{kg}$ once).

bacterial LPS lead to inhibition of testicular steroidogenesis and disruption of spermatogenesis in animals treated with LPS $^{9,33}$ or with septic agents that generate LPS. ${ }^{18}$ Moreover, it has been reported that LPS administration resulted in the disruption of the blood-testis barrier and increased infiltration of white blood cells (WBCs) with subsequent production of ROS and activation of NO synthase. ${ }^{12}$ In addition, it has been reported that antisperm antibody production is induced in the male genital tract when a local infection or disruption in the genital tract physical barrier leads to an influx of $\mathrm{CD}^{+} \mathrm{T}$ cells with subsequent production of proinflammatory cytokines. ${ }^{7}$ Moreover, numerous in vitro studies have established that Sertoli cells and Leyding cells secrete inflammatory cytokines and NO in response to LPS and other inflammatory stimuli. ${ }^{10,34}$ Furthermore, increased IL-2 level has been also reported as a potential marker for the male. ${ }^{35}$ On the other hand, Ochsendorf ${ }^{12}$ reported an increased testicular level of IL-2 during infection. These effects may help to explain that the unique testicular immune structure could be disturbed by LPS.

The increased testicular levels of MDA and NO in LPS-treated rats may be due to the fact that released inflammatory mediators individually enter the local process and intensify the redox imbalance, initially in the reproductive tract and later in the semen, which determines the magnitude of the interaction between toxic oxygen metabolites and cell macromolecules, and which in consequence affects the fertilizing potential of germ cells. ${ }^{16}$ Also, it has been documented that ROS overproduction associated with inflammatory reactions may be primarily caused by pathological bacterial strains that colonize or infect the reproductive tract. ${ }^{36,37}$ In addition, previous studies explained that processes that are crucial for fertilization, such as sperm hyperactivation, phosphorylation of tyrosine kinases during sperm capacitation, and the activation of cellular phospholipase $A_{2}$ in the acrosomal reaction, are strictly regulated by the redox system of spermatozoa. ${ }^{38}$ The destructive effect of oxidative stress on male gametes is mainly associated with the peroxidative processes of sperm membrane components and DNA fragmentation. ${ }^{6,39}$ This may explain the present data which shows a marked increase in the level of 8-HDG in testicular derived DNA, a specific DNA adduct for oxidative DNA damage in LPS-treated rats.
However, the peroxidation of sperm membrane lipids is generally considered as the first marking point of germ cell damage induced by reactive oxygen intermediates, which in turn may lead to sperm dysfunction that results in the inability of sperm to penetrate the oocyte. ${ }^{40}$ Some authors have suggested that particular cytokines modulate the expression of genes responsible for the redox system in semen. ${ }^{41}$ In that aspect, an increase in ROS production by human sperm was observed after the addition of IL-1, IL-1 $\beta$ or TNF $\alpha$, the result of which was an increase in sperm membrane lipid peroxidation, as measured by the MDA level. ${ }^{42}$ Furthermore, it has been reported that the overproduction of proinflammatory cytokines may be dangerous both to the cells of the immune system as well as to other cells and tissues of the body through the induction of cell apoptosis. ${ }^{43}$ The recent study of Mahfouz et al. ${ }^{44}$ explained that oxidative stress induced sperm damage in the form of apoptosis. Also, it has been reported that in vitro exposure of human sperm to hydrogen peroxide reduced sperm motility, sperm viability, reacted acrosome and induced lipid peroxidation in spermatozoa. ${ }^{45}$ Moreover, Tremellen ${ }^{46}$ explained that free radicals and peroxides generated within semen could produce infertility by two key mechanisms. First, they damage the sperm membrane, decreasing sperm motility and its ability to fuse with the oocyte. Second, alteration of the sperm DNA, resulting in the passage of defective paternal DNA on to the conceptus. On the other hand, it was found that LDH-x, a unique isoenzyme of lactate dehydrogenase, in the inner mitochondrial membrane of the spermatogenic cells of mature and developing testis, plays an important role in transferring hydrogen from cytoplasm to mitochondria by redox coupling $\alpha$-hydroxy acid/ $\alpha$-keto acid related to spermatozoal metabolism. ${ }^{47}$ In our study, the decreased LDH-x activity may be a consequence of the enhanced lipid peroxidation after exposure to LPS may be due to disintegration of the mitochondrial membrane ultrastructure which in turn affects the membrane bound LDH-x function. This explanation can be augmented by the study of Verma et al. ${ }^{48}$ who reported a positive correlation between LDH-x activity and sperm count which is also proved in the present study.

For the last decade, L-carnitine has been used as an additive for various therapeutic regimes against infectious diseases. ${ }^{49}$ The 
molecular mechanisms underlying these effects are not fully understood. The proposed antioxidative and immunoregulator role of L-carnitine during sepsis leads us to find whether L-carnitine supplementation counteract LPS-induced male infertility in rats. Our data revealed that L-carnitine could protect against LPS-induced testicular toxicity which, approved by normalization of sperm number and motility, increased activity of $\mathrm{LDH}_{\mathrm{x}}$ and improved histological features of the testis. In addition, L-carnitine administration resulted in decreased serum levels of IL-2 and testicular MDA as well as NO with a concomitant restoring testicular GSH content in comparison with LPS-exposed rats. Moreover, L-carnitine markedly reduced 8-HDG in the testicular DNA in LPS-treated animals.

The obtained data are in agreement with the previous study of Kumar et al. ${ }^{50}$ who proposed that carnitine enhances sperm energy production and, therefore, motility. By regulating carbohydrate metabolism, L-carnitine is involved in the maintenance of cell membrane structure and cell viability and has been reported to reduce the apoptotic levels of $\mathrm{CD}^{+}$and $\mathrm{CD}^{+}{ }^{+}$cells. ${ }^{51} \mathrm{~L}$-carnitine has been shown to increase sperm count and motility in patients with an ultrasound picture of genital inflammation and leukocyte sperm concentration. ${ }^{52}$ Carnitine also has been reported to have an antioxidant capacity and protects sperm from oxidative damage. ${ }^{53}$ In addition, De Rosa et al. ${ }^{29}$ reported a significant positive correlation between seminal carnitine concentration and sperm concentration, total sperm count, sperm total motility, rapid forward progression, live sperm count, membrane function, nuclear DNA integrity, capacity for cervical mucus penetration, linearity of spermatic movement and amplitude of lateral sperm head movement. It has been proven that dietary L-carnitine supplementation significantly ameliorated the primary and secondary antigen-specific IgG response to bovine serum albumin in broiler chickens ${ }^{55}$ and in pigeons. ${ }^{54}$ Recently, Deng et al. ${ }^{55}$ confirmed the stimulating properties of dietary L-carnitine on humoral immunity in layingtype chickens. However, the latter investigators could not find evidence for any effects of L-carnitine on cell-mediated immune responsiveness. The study of Athanassakis et al. ${ }^{56}$ explained that L-carnitine administration to mice affects humoral and cellular immune responses by decreasing interleukin-2 (IL-2) production in response to a specific antigenic stimulus.

Moreover, treatment with carnitines improved sperm forward motility and viability in prostato-vesiculo-epididymitis patients with normal seminal WBC concentration, besides significantly increasing their otherwise poor reproductive performance. ${ }^{57}$ These effects may be explained by a re-equilibrium of the seminal oxidative balance resulting from an amelioration of the scavanger properties of the epididymal microenvironment. The associated reduction in ROS over-production supports the hypothesis that these alterations may be caused by plasma membrane peroxidative damage and/or abnormal or unbalanced levels of pro-inflammatory cytokines. At the same time it could be suggested that L-carnitine may re-establish an equilibrium between pro-inflammatory and antiinflammatory cytokines, reducing the former and/or increasing the latter. In the present study it could be hypothesized that L-carnitine administration affects humoral and cellular immune responses by maintaining the integrity of blood-testis barrier and prevents over-penetration of WBCs and subsequent production of ROS and inflammatory cytokines. It has been reported that the increased oxidative stress leads to increased activity of $\mathrm{NO}$ synthase and xanthine oxidase enzymes in the testis of infected rats with the subsequent formation of aggressive peroxynitrile and hydroxyl radicals. Therefore, in our study it could be suggested that L-carnitine confers antioxidant activity that reduced the testicular levels of NO, MDA as well as 8-HDG in addition to the healthy sperms and histology.

In conclusion, LPS induced cellular and humoral immunity in the testis as a result of oxidative burst which is regulated by several cytokines and prooxidant mechanisms with subsequent impairment of testicular functions. L-carnitine administration ameliorates these effects through reduction of IL-2 and by buffering the oxidative stress-induced damage. This may suggest its testicular protective effects during severe infection or sepsis.

\section{Materials and Methods}

Chemicals. Lipopolysaccaride (LPS) and L-carnitine (LCR) were purchased from Sigma chemical Company (St. Louis, MO). Thiobarbituric acid (TBA) was a product of Fluka (Buchs, Switzerland). All the remaining chemicals were of the highest analytical grade commercially available.

Animals. Male Swiss albino rats, weighing 200-250 g were obtained from the Experimental Animal Care Center, College of Pharmacy, King Saud University, Riyadh, KSA. Animals were maintained under standard conditions of temperature $24+1^{\circ} \mathrm{C}$ and $55+5 \%$ relative humidity with regular $12 \mathrm{~h}$ light: $12 \mathrm{~h}$ dark cycle and allowed free access to standard laboratory food (Purina Chow) and water.

Experimental protocol. Sixty rats were divided into four groups each consisted of 15 rats. The first group served as a control and received Saline; the $2^{\text {nd }}$ group was given LCR $(500 \mathrm{mg} / \mathrm{kg}$ i.p once). The third group was treated with LPS ( $5 \mathrm{mg} / \mathrm{kg}$ i.p once) and the fourth group received LCR then LPS after three hours..$^{58}$ Blood samples were collected by direct withdrawal from the heart by means of heparinized syringes. Five rats from each group were used for histopathological examination. Biochemical parameters were assessed in the remaining ten rats. At the end of the experiment, animals were lightly anaesthetized with ether where blood samples were collected and testes were dissected on ice. Sperm count and motility were evaluated from cauda epididymis in each animal. Also, oxidative stress was evaluated by measuring testicular contents of reduced glutathione (GSH), malondialdehyde (MDA) and 8-hydroxydeoxyguanosine (8-HDG, the DNA adduct for oxidative damage) in testicular DNA. The pro-inflammatory mediator nitric oxide $(\mathrm{NO})$ in addition to lactate dehydrogenase $(\mathrm{LDHx})$ isoenzyme-x activity as an indicator for normal spermatozoal metabolism were assessed in testicular homogenate. Serum interlukin (IL)-2 level was also assessed as a marker for T-helper cell function. Isoenzyme-x activity, as an indicator for normal spermatozoal metabolism, was assessed in testicular homogenate. Serum interlukin (IL)-2 level was also assessed as a marker for T-helper cell function. 
Determination of GSH content in testicular tissue. Tissue levels of acid soluble thiols, mainly reduced glutathione (GSH), were determined colorimetrically at $412 \mathrm{~nm}$ according to Ellman. ${ }^{59}$ Briefly, $0.5 \mathrm{ml}$ of previously prepared homogenate was added to $0.5 \mathrm{ml}$ of $5 \%$ trichloroacetic acid and after centrifugation at 3,000 $\mathrm{rpm}$ for five minutes, the supernatant $(200 \mu \mathrm{l})$ was added to a tube containing $1750 \mu \mathrm{l}$ of $0.1 \mathrm{M}$ Pot.phospate buffer, ( $\mathrm{pH}$ 8) and $50 \mu \mathrm{l}$ DTNB reagent. The tubes were mixed and the developed yellow color was measured against the standard curve of reduced glutathione. Protein thilos (protein-SH) were expressed as $\mu \mathrm{mol} / \mathrm{g}$ tissue.

Determination of lipid peroxides (MDA) in testicular homogenate. Tissue lipid peroxides level was determined as thiobarbituric acid-reactive substances. ${ }^{60}$ Tissue homogenates were prepared as previously mentioned above. Then, $0.1 \mathrm{ml}$ of the homogenate was added to a tube containing $1.5 \mathrm{ml}$ acetic acid $(20 \%, \mathrm{pH} 3.5), 0.2 \mathrm{ml}$ sodium dodecylsulphate, SDS, (8.1\%), $1.5 \mathrm{ml}$ TBA (0.8\%) and $0.7 \mathrm{ml}$ water against blank. The tubes were mixed and incubated in a water bath at $95^{\circ} \mathrm{C}$ for 60 min using glass balls as condensers. All the tubes were cooled, centrifuged at 4,000 rpm for $10 \mathrm{~min}$. The absorbance was measured photometrically at $532 \mathrm{~nm}$ in the supernatant and the concentrations are expressed as nmole malondialdehyde (MDA)/g tissue.

Determination of nitric oxide (NO) in testicular homogenates. Testicular NO was measured as nitrite/nitrate as described by Miranda et al. ${ }^{61}$ In brief, from the previously prepared testis homogenate, $0.5 \mathrm{ml}$ was added to $0.5 \mathrm{ml}$ of absolute ethanol then centrifuged at $4,000 \mathrm{rpm}$ for $10 \mathrm{~min}$. Then to $300 \mu \mathrm{l}$ of the supernatant $300 \mu \mathrm{l}$ of vanadium chloride $(\mathrm{VCl} 3,0.8 \%$ in 1 $\mathrm{M} \mathrm{HCl}$ ) was added. Then $300 \mu \mathrm{l}$ of a mixture of Griess 1 and 2 reagents 1:1, and $100 \mu \mathrm{l}$ of their solvents were added. Griess 1 reagent composed of $\mathrm{N}$-(1-naphthyl)-ethylenediamine (NEDD, $0.1 \%$ in distilled water) and Griess 2 composed of sulfanilamide, $2 \%$ in $5 \% \mathrm{HCl}$. The mixture was left at room temperature for 30-35 min then the color was measured spectrophotometrically at $540 \mathrm{~nm}$ against blank. Concentrations of $\mathrm{NO}$ (nmol/g tissue) were determined from a standard curve of different concentrations of sodium nitrite.

Determination of 8-hydroxy-2'-deoxyguanosine (8-HDG), a DNA adduct in testicular-extracted DNA. Testis DNA was extracted by phenol/chloroform/isoamyl alcohol. ${ }^{62}$ Briefly $3 \mathrm{ml}$ of previously prepared testis homogenate was stilled down by centrifugation at $1,000 \mathrm{rpm}$ for five minutes then washed with phsophate buffered saline (PBS) $\mathrm{pH} 7.4$. To the pellet $2 \mathrm{ml}$ of Tris-EDTA (TE) buffer [1 M Tris-HCl pH $8(100 \mathrm{ml})$ and $0.5 \mathrm{M}$ EDTA $(100 \mathrm{ml})$ were mixed and completed to $300 \mathrm{ml}$ with distilled water] was added. Then added was $100 \mu \mathrm{l}$ protinase $\mathrm{K}$ $(10 \mathrm{mg} / \mathrm{ml}$ ) and $240 \mu \mathrm{l} 10 \%$ SDS (sodium dodecylsulphate), shaken gently and incubated at $45^{\circ} \mathrm{C}$ in a water bath overnight. Then $2.4 \mathrm{ml}$ equilibrated phenol was added, shacked and centrifuged at 3,000 rpm for $10 \mathrm{~min}$. The supernatant was transferred to a new tube and $1.2 \mathrm{ml}$ of phenol then $1.2 \mathrm{ml}$ of chloroform/ isoamyl alcohol (24:1) were added, shacked for 5-10 min and centrifuged at 3,000 rpm for $10 \mathrm{~min}$. The supernatant was transferred to a new tube and $2.4 \mathrm{ml}$ of chloroform/isoamyl alcohol
(24:1) was added and shacked for 5-10 min then centrifuged at $3,000 \mathrm{rpm}$ for $5-10 \mathrm{~min}$. To the supernatant $25 \mu \mathrm{l}$ of sodium acetate (3 M, pH 5.2) and $5 \mathrm{ml}$ of cold absolute ethanol were added with gentile shaking, DNA was precipitated. The DNA was hooked out and washed with ethanol then dissolved in TE buffer and the concentration was obtained by determination of the absorbance at $260 \mathrm{~nm}$. The purity of extracted DNA was determined by assessment of the ratio of the absorbance at 260/280. Purity of extracted DNA was above 97\%. Extracted DNA was digested by DNase-1 (1 U/1 $\mu \mathrm{g}$ DNA). Digested DNA was subjected to determination of 8-HDG according to the protocol of the commercially available Kit by ELIZA assay (BIOXYTECH, 8-HDG-EIA Kit, OXIS, Health Product. Inc., 6040 N Cutter Circle, Suite 317 Portland, OR 97217-3935 USA).

Assessment of IL2. IL-2 was assayed in serum by ELISA according to the procedure described by the instructions of the commercial Kit (Abcam Ltd., 332 Cambride Science Park, Milton Road, Cambridge CB4 OFW, UK).

Histopathological examinations. Testes were collected and fixed in $10 \%$ formalin in phosphate buffer saline, $(\mathrm{pH} 7)$ for $24 \mathrm{~h}$ at room temperature. Then, the tissues were embedded in paraffin wax and sections were cut at $5 \mu \mathrm{m}$ thickness and stained with hematoxylin-eosin stains by routine procedures. A histopathologist who was unaware of the treatments examined the coded slides by a light microscope and recorded the histopathological lesions and photographed them.

Statistical analysis. Data are expressed as means \pm SEM $(\mathrm{n}=10)$. Statistical comparison between different groups were done by using Graph Pad Prism4 software through one way analysis of Variance (ANOVA) followed by Tukey-Kramer for multiple comparisons test to judge the difference between different groups. Significance level was accepted at $\mathrm{p}<0.05$.

\section{References}

1. Naito M, Itoh M. Patterns of infiltration of lymphocytes into the testis under normal and pathological conditions in mice. Am J Reprod Immunol 2008 59:55-61.

2. Fijak M, Meinhardt A. The testis in immune privilege. Immunol Rev 2006; 213:66-81.

3. Itoh $M$, Terayama $H$, Naito $M$, Ogawa $Y$, Tainosho S. Tissue microcircumstances for leukocytic infiltration into the testis and epididymis in mice. J Reprod Immunol 2005; 67:57-67.

4. Pacey AA, Eley AA. Chlamydia trachomatis and male fertility. Hum Fertil 2004; 7:271-6.

5. Reddy MM, Mahipal SV, Subhashini J, Reddy MC, Roy K, RReddy GV, et al. Bacterial lipopolysaccharide-induced oxidative stress in the impairment of steroidogenesis and spermatogenesis in rats. Reprod Toxicol 2006; 22:493-500.

6. Comphaire FH, Mahmoud AM, Depuydt CE, Zalata AA, Christophe AB. Mechanisms and effects of male genital tract infection on sperm quality and fertilizing potential: The andrologist's viewpoint. Hum Reprod Update 1999; 5:393-8.

7. Witkin SS, Jeremias J, Bongiovanni AM, Munoz MG. Immune regulation in the male genital tract. Infect Dis Obstet Gynecol 1996; 4:131-5.

8. O'Bryan MK, Schlatt S, Phillips DJ, de Kretser DM, Hedger MB. Bacterial lipopolysaccharide-induced inflammation compromises testicular function at multiple levels in vivo. Endocrinol 2000; 141:238-46.

9. Wallgren M, Kindahl H, Rodriguez-Martinez $\mathrm{H}$. Alterations in testicular function after endotoxin injections in the boar. Int J Androl 1993; 16:235-43.

10. Jégou B, Cudicini C, Gomez E, Stéphan JP. Interleukin-1, interleukin-6 and the germ cell-Sertoli cell cross-talk. Reprod Fertil Dev 1995; 7:723-30.

11. Gruschwitz MS, Brezinschek R, Brezinschek HP. Cytokine levels in the seminal plasma of infertile males. J Androl 1996; 17:158-63.

12. Ochsendorf RF. Infections in the male genital tract and reactive oxygen species. Hum Reprod Update 1999; 5:399-20.

13. Wang A, Fanning L, Anderson DJ, Loughlin KR. Generation of reactive oxygen species by leukocytes and sperm following exposure to urogenital tract infection. Arch Androl 1997; 39:11-7. 


\section{L-carnitine rebalances immune-testicular barrier in septic rats}

14. Rajasekaran M, Hellstrom WJ, Naz RK, Sikka SC. Oxidative stress and interleukins in seminal plasma during leukocytospermia. Fertil Steril 1995; 64:166-71.

15. Sanocka D, Fraczek M, Jedrzejczak P, Szumala-Kakol A, Kurpisz M. Male genital tract infection: An influence of leukocytes and bacteria on semen. J Reprod Immunol 2004; 62:111-24.

16. Fraczek M, Kurpisz M. The redox system in human semen and peroxidative damage of spermatozoa. Postepy Hig Med Dosw 2005; 59:523-34.

17. Agarwal A, Saleh RA, Bedaiwy MA. Role of reactive oxygen species in the pathophysiology of human reproduction. Fertil Steril 2003; 79:829-43.

18. Sharma RK, Pasqualotto FF, Nelson DR, Thomas AJ, Agarwal A. The reactive oxygen species-total antioxidant capacity score is a new measure of oxidative stress to predict male infertility. Hum Reprod 1999; 14:2801-7.

19. Kim SK, Yoon YD, Park YS, Ju Tae Seo JT, Kim JH. Involvement of the Fas-Fas ligand system and active caspase- 3 in abnormal apoptosis in human testes with maturation arrest and Sertoli cell-only syndrome. Fertil Steril 2007; 87:547-53.

20. Lin WW, Lamb DJ, Wheeler TM, Lipshultz LL, Kim ED. In situ end-labeling of human testicular tissue demonstrates increased apoptosis in conditions of abnormal spermatogenesis. Fertil Steril 2007; 68:1065-9.

21. Takagi S, Itoh N, Kimura M, Sasao T, Tsukamoto T. Spermatogonial proliferation and apoptosis in hypospermatogenesis associated with nonobstructive azoospermia. Fertil Steril 2001; 76:901-7.

22. Bremer J. Carnitine metabolism and functions. Physiol Rev 1983; 63:142-80.

23. Famularo G, Marticardi F, Nucera E, Santini G, De Simone C. Carnitine deficiency: Primary and secondary syndromes. In: De Simone C and Famularo G, Editors, Carnitine Today, Landes Bioscience and Chapman \& Hall, New York 1977; 120-61.

24. Foster DW. The role of the carnitine system in human metabolism. Ann NY Acad Sci 2004; 1033:1-16.

25. Abd-Allah AR, Al-Majed AA, Al-Yahya AA, Fouda SI, Al-Shabana OA. L-Carnitine halts apoptosis and myelosuppression induced by carboplatin in rat bone marrow cell cultures (BMC). Arch Toxicol 2005; 79:406-13.

26. Liu J, Head E, Kuratsune H, Cotman CW, Ames BN. Comparison of the effects of l-carnitine and acetyl-l-carnitine on carnitine levels, ambulatory activity and oxidative stress biomarkers in the brain of old rats. Ann NY Acad Sci 2004; 1033:117-31.

27. Buyse J, Swennen Q, Niewold TA, Klasing KC, Janssens GPJ, Baumgartner M, et al. Dietary l-carnitine supplementation enhances the lipopolysaccharide-induced acute phase protein response in broiler chickens. Veterinary Immunol Immunopathol 2007; 118:154-9.

28. Li K, Li W, Huang YF, Shang XJ. Level of free L-carnitine in human seminal plasma and its correlation with semen quality. Zhonghua Nan Ke Xue 2007; 13:143-6.

29. De Rosa M, Boggia B, Amalfi B, Zarrilli S, Vita A, Colao A, Lombardi G. Correlation between seminal carnitine and functional spermatozoal characteristics in men with semen dysfunction of various origins. Drugs R D 2005; 6:1-9.

30. Aslesci S, De Martino MU, Kino T, Ilias I. L-Carnitine is a modulator of the glucocorticoid receptor alpha. Ann N Acad Sci 2004; 1024:147-52.

31. Manoli L, De Martino MU, Kino T, Alesci S. Modulatory effects of L-carnitine on glucocorticoid receptor activity. Ann NY Acad Sci 2004; 1033:147-57.

32. Schulz M, Eggert M. Novel ligands: Fine tuning the transcriptional activity of the glucocorticoid receptor. Curr Pharm Des 2004; 10:2817-26.

33. Tulassay Z, Viczián M, Böjthe L, Czeizel A. Quantitative histological studies on the injury of spermatogenesis induced by endotoxin in rats. J Reprod Fertil 1970; 22:161-4.

34. Okuda Y, Bardin CW, Hodgskin LR, Morris PL. Interleukins-1 and - $1 \beta$ regulate interleukin-6 expression in Leydig and Sertoli cells. Recent Prog Horm Res 1995; 50:367-72.

35. Feldmann M, Saklatvala J. Proinflammatory cytokines. In:Oppenheim JJ \& Feldman M, eds. Cytokine Reference. New York: Academic Press 2001; 291-305.

36. Keck C, Gerber-Schafer C, Clad A, Wilhelm C, Breckwoldt M. Seminal tract infections: impact on male fertility and treatment options. Hum Reprod Update 1998; 4:891-903.

37. Potts JM, Sharma R, Pasqualotto F, Nelson D, Hall G, Agarwal A. Association of ureaplasma urealyticum with abnormal reactive oxygen species levels and absence of leukocytospermia. J Urol 2000; 163:1775-8

38. Leclerc E, de Lamirande E, Gagnon C. Regulation of protein-tyrosine phosphorylation and human sperm capacitation by reactive oxygen derivatives. Free Radic Biol Med 1997; 22:643-56.

39. Aitken RJ. The Amoroso Lecture. The human spermatozoon-A cell in crisis? J Reprod Fertil 1999; 115:1-7.

40. Sanocka D, Kurpisz M. Reactive oxygen species and sperm cells. Reprod Biol Endocrinol 2004; 2 : 12 .

41. Shimoya K, Matsuzaki N, Tsutsui T, Taniguchi T, Saji F, Tanizawa O. Detection of interleukin-8 (IL-8) in seminal plasma and elevated IL-8 in seminal plasma of infertile patients with leukospermia. Fertil Steril 1993; 59:885-8.

42. Buch JP, Kolon TF, Maulik N, Kreutzer DL, Das DK. Cytokines stimulate lipid membrane peroxidation of human sperm. Fertil Steril 1994; 62:186-8.

43. Fraczek M, Kurpisz M. Inflammatory mediators exert toxic effects of oxidative stress on human spermatozoa. J Androl 2007; 28:325-33.
44. Mahfouz RZ, du Plessis SS, Aziz N, Sharma R, Sabanegh E, Agarwal A. Sperm viability, apoptosis and intracellular reactive oxygen species levels in human spermatozoa before and after induction of oxidative stress. Fertil Steril 2008; PMID:19100530.

45. Fatma BA, Nozha CF, Ines D, Hamadi A, Basma H, Leila AK. Sperm quality improvement after date seed oil in vitro supplementation in spontaneous and induced oxidative stress. Asian J Androl 2009; PMID:19151733.

46. Tremellen K. Oxidative stress and male infertility-A clinical perspective. Hum Reprod Update 2008; 14:243-58.

47. Gu Y, Davis DR, Lin YC. Developmental changes in lactate dehydrogenase-X activity in young jaundiced male rats. Arch Androl 1989; 22:131-6.

48. Verma PK, Singh JN, Quadros M. LDH-X in azospermia: A new diagnostic alternative to vasography and testicular biopsy. Indian J Med 1993; 97:204-7.

49. Kumar R, Gautam G, Gupta NP. Drug therapy for idiopathic male infertility: Rationale versus evidence. J Urol 2006; 176:1307-12.

50. Famularo G, De Simone C, Trinchieri V, Mosca L. Carnitine and its congeners. A metabolic pathway to the regulation of immune response and inflammation. Ann NY Acad Sci 2004; 1033:1-7.

51. Simone C, Tsantzoglou S, Famularo G, Moretti S, Paoletti F, Vullo V, Delia S. High dose l-carnitine improves immunologic and metabolic parameters in AIDS patients. Immunopharmacol Immunotoxicol 1993; 15:1-12

52. Cavallini G, Modenini F, Vitali G, Koverech A. Acetyl-L-carnitine plus propionyl-Lcarnitine improve efficacy of sildenafil in treatment of erectile dysfunction after bilateral nerve-sparing radical retropubic prostatectomy. Urology 2005; 66:1080-5.

53. Mast J, Buyse J, Goddeeris BM. Dietary l-carnitine supplementation increases antigenspecific immunoglobulin G production in broiler chickens. Br J Nutr 2000; 83:161-6.

54. Janssens GPJ, Mast J, Goddeeris BM, Cox E, Hesta M, De Wilde ROM. Enhanced specific antibody response to bovine serum albumin in pigeons due to l-carnitine supplementation. Br Poult Sci 2000; 41:448-53

55. Deng K, Wong CW, Nolan JV. Long-term effects of early-life dietary l-carnitine on lymphoid organs and immune responses in Leghorn-type chickens. J Anim Physiol Anim Nutr 2006; 90:81-6.

56. Athanassakis I, Mouratidou M, Sakka P, Evangeliou A, Spilioti M, Vassiliadis S. L-carnitine modifies the humoral immune response in mice after in vitro or in vivo treatment. Int Immunopharmacol 2001; 1:1813-22.

57. Vicari E. Effectiveness and limits of antimicrobial treatment on seminal leukocyte concentration and related reactive oxygen species production in patients with male accessory gland infection. Hum Reprod 2000; 15:2536-44.

58. Abd-Allah AR. L-carnitine ameliorates immunological-induced hepatitis in rats. Saud Pharmaceutical Journal 2006; 14:59-68.

59. Ellman GL. Tissue sulfhydryl groups. Arch Biochem Biophys 1959; 82:70-7.

60. Uchiyama M, Mihara M. Determination of malondialdehyde precursor in tissues by thiobarbituric acid test. Anal Biochem 1978; 86:271-8.

61. Miranda KM, Espey MG, Wink DA. A rapid, simple spectrophotometric method for simultaneous detection of nitrate and nitrite. Nitric Oxide 2001; 5:62-7.

62. Racevskis J. Molecular diagnosis of cancer: Methods and Protocols; second edition. Med Oncol 2005; 22:325-6. 


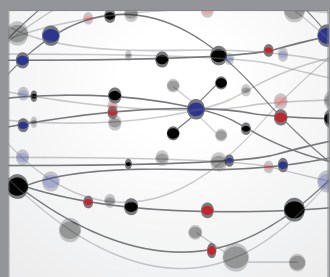

The Scientific World Journal
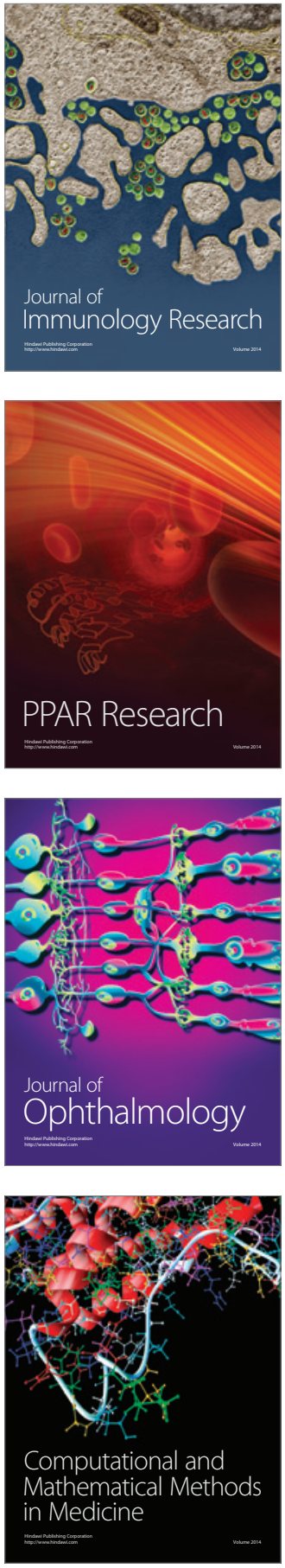

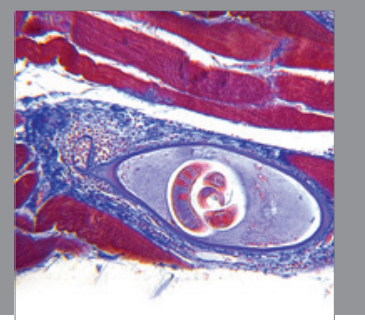

Gastroenterology

Research and Practice
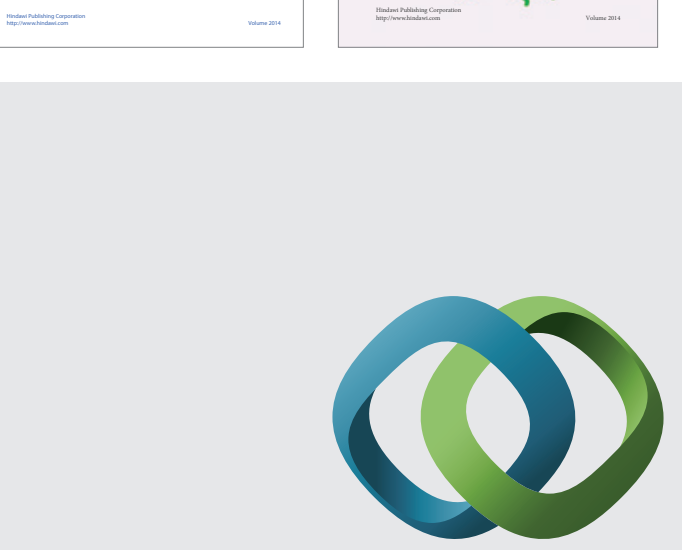

\section{Hindawi}

Submit your manuscripts at

http://www.hindawi.com
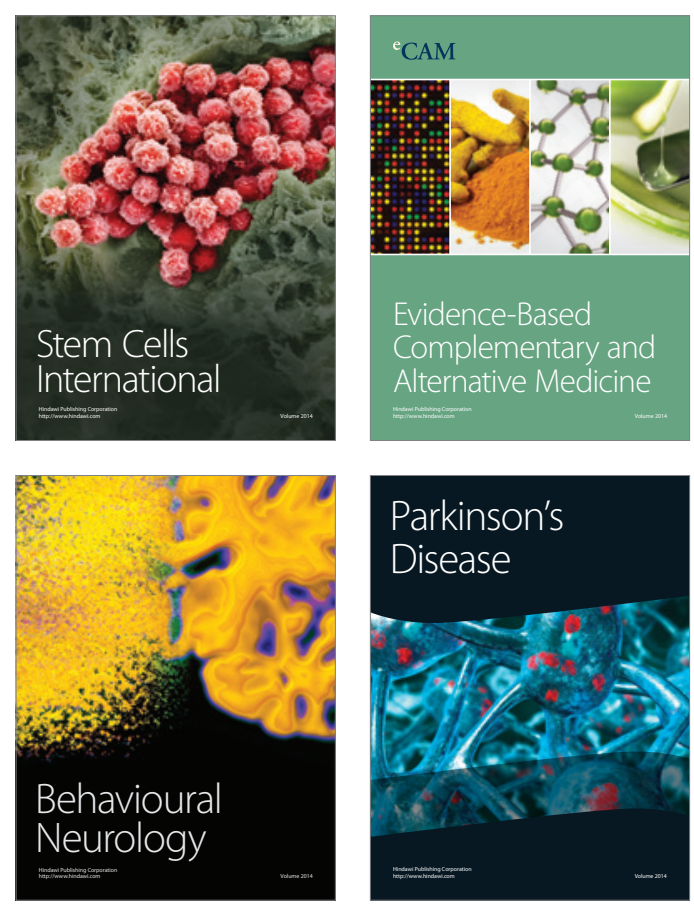

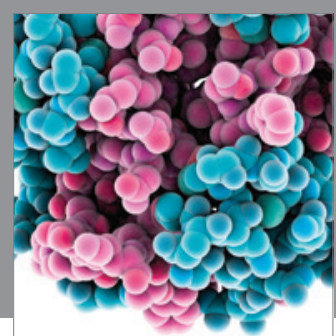

Journal of
Diabetes Research

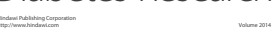

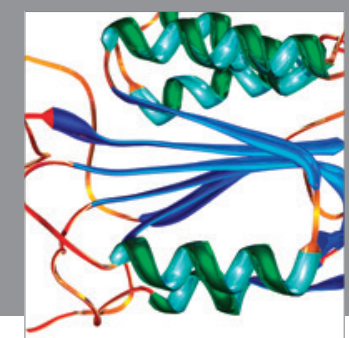

Disease Markers
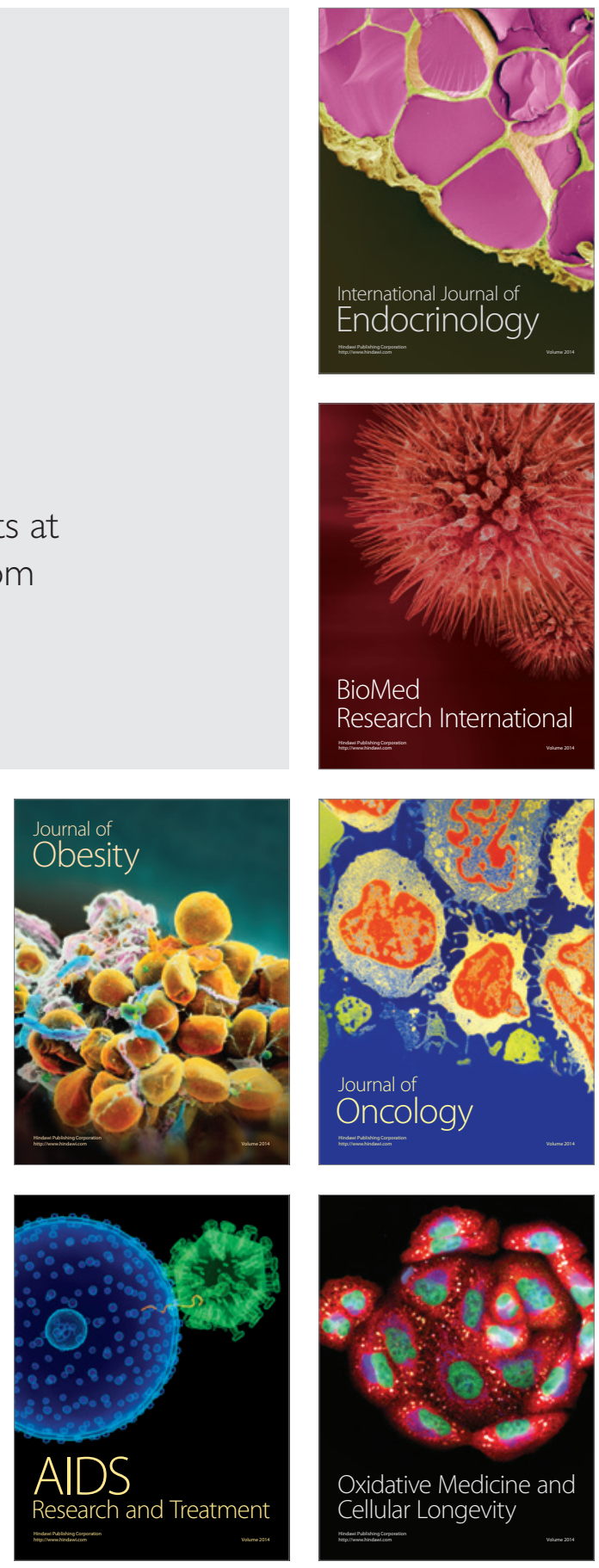